\title{
The Great Commentary (Dazhuan 大傳) and Chinese natural cosmology
}

\author{
Roger T. Ames 安樂哲
}

Received: 19 January 2015/Revised: 17 February 2015/ Accepted: 17 February 2015 /

Published online: 5 March 2015

(C) Academy for International Communication of Chinese Culture 2015

\begin{abstract}
As important as the Daoist and Confucian canons have been in the articulation of Chinese intellectual history and as much as they can be appealed as textual evidence for claims about early Chinese cosmology, perhaps no single text can compete with the Yijing 易經 or Book of Changes in terms of the sustained interest it has garnered from succeeding generations of China's literati, and the influence it has had on Chinese self-understanding. The coordination of the relationship between the changing world and the human experience is the main axis of the Yijing. The purpose of this text is fundamentally normative and prescriptive. It purports to address life's most pressing question: What kind of participation in these natural processes can optimize the possibilities of a world in which natural and human events are two inseparable, mutually shaping aspects? Confucian morality itself is a cosmic phenomenon that emerges from the synergistic transactions that take place between the operations of nature and human effort.
\end{abstract}

Keywords Yijing - Dazhuan · Chinese natural cosmology · Focus and field . Correlative thinking $\cdot$ Ars contextualis

As important as the Daoist and Confucian canons have been in the articulation of Chinese intellectual history and as much as they can be appealed as textual evidence for claims about early Chinese cosmology, perhaps no single text can compete with the Yijing 易經 or Book of Changes in terms of the sustained interest it has garnered from succeeding generations of China's literati, and the influence it has had on Chinese self-understanding. The Yijing has been and still remains, in every sense, the first among the Chinese classics. Indeed, it is this open-ended classic with its

R. T. Ames 安樂哲 ( $\square)$

Department of Philosophy, University of Hawai'i, 2530 Dole Street, Honolulu, HI 96822, USA

e-mail: rtames@hawaii.edu 
centuries of accruing commentaries that has set the terms of art for Chinese cosmology.

The Yijing is a complex text that includes both a manual used as heuristic for making correlations, and seven appended commentaries. Since three of these commentaries are divided into two sections each, in sum they are often referred to as the "Ten Wings." The manual, used traditionally as an instrument for pursuing productive correlations, is of a much earlier vintage than the commentaries, and has come to be referred to independently as the Zhouyi 周易.

Although the commentaries are themselves composite and sometimes fragmentary, and certainly belong to a much later period than the manual itself, portions of them are hugely important as a summary statement of an early Chinese cosmology that has had a persisting influence on the Chinese sense of its world. One of these commentaries, the Xici 繋辭, also called the Great Commentary 大傳, is perhaps the most important source we presently have for exploring early Chinese cosmology. Given that a silk manuscript version of it dating from 168 BCE was found at the Mawangdui site in Changsha in 1973, we have at least a terminus ad quem for its compilation.

Willard Peterson in analyzing this profound, protean, and frustratingly opaque document-the Great Commentary-insists that it "has been for some 2000 years one of the most important statements in the Chinese tradition on knowing how the cosmos works and how humans might relate to that working. Especially from the Sung [Song] through the Ch'ing [Qing] periods, the 'Great Commentary' ('Ta chuan [Dazhuan]'), as it was called, provided the locus classicus for vocabulary and concepts in nearly every major abstract discussion of the physical world and man's place in it." 1

Edward Shaughnessy in his retranslation of the Great Commentary based on the Mawangdui materials echoes Peterson's evaluation of its importance in observing that "the worldview of its Xici or Appended Statements Commentary-integrating man and nature through the medium of the Yijing-is arguably the most sophisticated (it is certainly the most subtle) statement of the correlative thought that has been so fundamental to all of China's philosophical systems."2 Shaughnessy is not exaggerating when he says that "indeed, so central has the Yijing been to Chinese thought over these two millennia that a history of its exegetical traditions would require almost a history of Chinese thought.",3

The Yijjing as a text is itself an object lesson in the worldview that it attempts to present. That is, when we reflect on the nature of particular "events" within this process worldview, the relationship between these particular foci and their fields lends itself to a holographic understanding of world systems. As Peterson suggests, the text of the Yijing itself as a particular foci "duplicates relationships and processes at work in the realm of heaven-and-earth," and thus provides those who understand it with a window on the workings of the cosmos. For it is the timely application of a knowledge of these same relationships and processes that "is the basis for

\footnotetext{
1 Peterson (1982, p. 67).

2 Shaughnessy (1997, p. 1).

3 Shaughnessy (1997, p. 1).
} 
efficacious action in the realm of human society." 4 As Peterson continues, "the Change [Yijing] is not separate from but equal to the cosmos, and it is in virtue of that relationship that it "works." "5 This same claim is made explicitly in the Great Commentary itself:

As a document, the Yijing is vast and far-ranging, and has everything complete within it. It contains the way of the heavens, the way of human beings, and the way of the earth. ${ }^{6}$

There is a cluster of key philosophical terms around which the Great Commentary is constructed. The world as immediately experienced provides us with a seemingly endless vocabulary of correlated binary terms: the high and the low, the moving and the still, the hard and the soft, the full and the empty, the large and the small, the bright and the dark, the hot and the cold, and so on. The correlative, bipolar, and dynamic tensions inherent in a world so defined circumscribe the domain within which the processes of change take place. And it is these same tensions that are the source out of which the novelty which attends these processes is produced. ${ }^{7}$

A familiar metaphor in the early corpus for the novel arising and subsiding of the always unique phenomena of the world are the "swinging gates of tian 天 門:”

Thus the closing of the swinging gate is called kun 坤; the opening of it is called qian 乾. The ongoing alternation of openings and closings is called flux (bian 變), and the inexhaustibility of the comings and goings is called continuity (tong 通). When something is manifest, it is called an image (xiang 象), and taking on physical form it is called a phenomenon ( $q i$ 器). To fashion and make use of these things is called emulation ( $f a$ 法). Putting them to good use in everything that is done so that all of the people can take advantage of them is called spirituality (shen 神). $^{8}$

\footnotetext{
${ }^{4}$ Peterson (1982, p. 85). Peterson in response to the question, "how can a divination text 'connect' with the cosmos?" allows that "duplicated" is "my feeble attempt to provide a necessarily inadequate name for the relationship." He goes on to describe rather clearly what I have called the holographic focus/field relationship between the cosmos and the Yijing:
}

They are each "one of two things" exactly alike, each a double of the other, each "has in it" the other. (1982, p. 91).

${ }^{5}$ Peterson (1982, p. 91).

${ }^{6}$ Great Commentary B8. In translating passages from the Yijing, I have had the benefit of consulting existing translations, particularly those of Peterson (1982) and Lynn (1994).

${ }^{7}$ The Yijing has served over the centuries as a heuristic for ordering the Chinese world, providing imagistic analogies and a vocabulary for reflection. Other canonical texts have functioned similarly as a source of analogy. See for example the "Attuning the Single Thread (zhengguan)" chapter of the Chunqiufanlu in which the Spring and Autumn Annals is described as functioning as a source of order in similar terms:

Thus we must be cognizant of how suitable its system are in practice. It is only when we understand its basic sentiments that we are able to digest its purposes; it is only when we understand its voice that we are able to promote its spirit; it is only when we understand its practices that we are able to follow its institutional forms.

${ }^{8}$ Great Commentary A11. 
This passage like so many in the Great Commentary begins from an observation about the ongoing natural processes, and then concludes with advice on how an effective collaboration with the changing world can inspire the human experience:

Thus, that which goes beyond form is called dao; those things that have form are called phenomena. The transforming and tailoring of things is called flux. The extending and applying of things is called continuity. To take up this understanding and bring it into the lives of the common people is called the grand undertaking. 9

The coordination of the relationship between the changing world and the human experience is the main axis of the Yijing. The purpose of this text is fundamentally normative and prescriptive. It purports to address life's most pressing question: What kind of participation in these natural processes can optimize the possibilities of a world in which natural and human events are two inseparable, mutually shaping aspects?

Confucian morality itself is a cosmic phenomenon that emerges from the synergistic transactions that take place between the operations of nature and human effort:

The greatest excellence (dade 大德) of the world is said to be its giving of life. The greatest treasure of the sage is said to be the attainment of standing (wei 位). The means of maintaining one's standing is being consummate in one's conduct (ren 仁). The means of attracting and gathering others is the use of resources. To regulate the available resources, to insure that language is used properly, and to prevent the people from doing wrong is called appropriateness (yi 義). ${ }^{10}$

Spirituality in the community arises from a penetrating understanding of the workings of change, and the quality of appropriate conduct that such an understanding can inspire. Simply put, spirituality is the product of inspired living: of reading initial conditions while they are still inchoate, anticipating their possibilities, and of aspiring to make the most of them. The "intensive" conduct of the exemplary person becomes "extensive" as it serves as a model for and is deferred to by the people:

Understanding the incipient ( $j i$ 幾) is spiritual insight (shen). That exemplary persons (junzi) are not obsequious in dealing with superiors or self-serving in dealing with subordinates is because they understand the incipient. The incipient is a hint of movement from which one can see in advance impending fortune. Exemplary persons having seen the incipient are aroused to action without waiting to see what happens... Exemplary persons in their understanding of both the inchoate and the obvious, of both the soft and the hard, make them a beacon for the myriad people. ${ }^{11}$

\footnotetext{
${ }^{9}$ Great Commentary A12.

${ }^{10}$ Great Commentary B1.

11 Great Commentary B4.
} 
In fact, it is a spirituality emerging from always appropriate and productive conduct that is the highest achievement humanity can aspire to:

No one has yet to figure out how to go beyond this, because making the most of spirituality (shen) and understanding the process of transformation is the fullness of excellence $(d e) .^{12}$

This Great Commentary in telling the story of its own origins explains how a human responsiveness to context has in past, and continues now to enchant the cosmos. The remote ancestors $\mathrm{Fu} \mathrm{Xi}$ and Shen Nong established a rhythm in the human experience, enabling them to chime in with the cadence of the "flux and continuity (biantong 變通)" that they perceived as persistent characteristics of the world around them. Inspired by the efficacy of their insights into the workings of the cosmos, they then represented their interpretation of life in the world, in a hexagramic language of images, models, and patterns for the benefit of generations yet to come. Importantly, these antique sages were engaged in a project of personal understanding and articulation rather than in some disinterested interrogation of nature.

According to the Yijing, when things run their course, there is flux (bian), where there is flux, there is continuity (tong), and where there is such continuity, it is enduring. ${ }^{13}$

By their efforts at ars contextualis - the art of effectively contextualizing and coordinating the experience of the human being within the processes of nature in their effort to optimize the creative possibilities of the cosmos- $\mathrm{Fu} \mathrm{Xi}$ and Shen Nong cultivated a thick continuity between nurture and nature expressed in the evocative images that constitute the Yijing. This perceived continuity between the human experience and the natural forum in which it occurs-between petroglyphs and the striations in stone, for example-is later made explicit in expressions such as "the continuity between the natural and the human 天人合一," and the "mutual responsiveness of the natural and the human 天人相應, 天人感應.” Importantly, these expressions report on the symbiotic mutuality of these dimensions of experience rather than on two originally separate aspects of the world being reconciled after the fact.

Indeed, this assumed continuity between nature and nurture is reflected in the fact that the same vocabulary is used to express the creative advance in both the human and the natural ecologies: for example, "the way of things (dao 道)," "vital energies ( $q i$ 氣)," “inscribed culture (wen 文)," “patterns (li 理)," “yinyang 陰陽,"and the perpetual interface between "flux and continuity (biantong 變通)" itself all reference both the human and the natural worlds. In this co-creative relationship with the world around us, there is no initial and originative Logos. Language and its significance emerges pari pasu with a world that it is continually being spoken into being. The process of making meaning, inspired by our imagination, becomes our reality, our imaginaire.

\footnotetext{
12 Great Commentary B3.

13 Great Commentary B2. .
} 
Building on this auspicious beginning, the sage kings descended from $\mathrm{Fu} \mathrm{Xi}$ and Shen Nong-the Yellow Emperor, Yao, and Shun-continued to construct technologies, modes of transportation, social institutions, and customs that were inspired by particular hexagrams, each of the hexagrams providing a dynamic image of some natural process:

The sages had the capacity to see the way the world operates, and perceiving the way things come together and commune, they put into practice their statutes and codes of propriety. ${ }^{14}$

It is this gradual and ongoing process of structuring and ritualizing the human experience thus remembered in and inspired by the Great Commentary that has enchanted life in the world, and in so doing, continues to produce its spirituality:

In comprehending the flux and flow of the world around them, the sage kings were able to save the people from exhausting themselves. With their spiritual insight (shen), they transformed the people, and enabled the people to find what was most fitting for them. ${ }^{15}$

The productive symbiosis that can be achieved between the human and the natural worlds is practical inspiration for effective human living. This ongoing production of human culture has transformed bird tracks and the markings on the backs of turtles into awe-inspiring calligraphy and the Book of Songs 詩經. It has elevated feeding into fine dining and the elegance of the tea house, and stirred raw sense data into heights of aesthetic expression. It has uplifted random copulation into love and family, made noise into the magic of sublime music, and inspired inchoate interpersonal relations into the flourishing community and the profound religious sensibilities that such human communion fosters.

In addition to enabling human beings to live moral and aesthetic lives, this understanding of the processes of change and productivity revealed by the Yijing allows them access to the very mysteries of the cosmos:

The Master asked rhetorically, "Does not the person who understands the course of flux and transformation in fact have insight into the workings of the spiritual?"16

Significant for our understanding of the role of religiousness, the enchanted, numinous dimension of the human experience (shen 神) does not belong to another world. Far from it, such spirituality is the inexhaustible product of human efficacy and refinement in this one:

The Yijing is the sage's means of probing what is profound to its very limits, and examining thoroughly what is still incipient ( $j i$ 幾). It is only through this profundity that the sages can discern the purposes of the world; it is only through the incipient that they can consummate the business of the world; it is

\footnotetext{
14 Great Commentary A6.

15 Great Commentary B2.

16 Great Commentary A9.
} 
only through insight into the spiritual they can be quick without haste and can arrive without even going. ${ }^{17}$

In the course of time, such high expectations of the human experience have produced what might be called an "a-theistic" religiousness - a religiousness without appeal to an independent, transcendent Deity as the source of order - that elevates the cultivated human experience into what the Zhongyong describes as cosmic proportions. Human beings, without reference to limiting assumptions about religious transcendentalism and supernaturalism, have become a source of profound meaning in their own world - the only world. Cosmic creativity is fully a collaboration between human beings and their own environing context, a cosmology that is consistent with what John Berthrong calls "the world-dependent nature of divine reality."18

Indeed, it is the cosmic import of human co-creativity that moves the Zhongyong to its religious crescendo:

Only those in the world of utmost creativity (zhicheng 至誠) are able to separate out and braid together the many threads on the great loom of the world. Only they set the great root of the world and realize the transforming and nourishing processes of heaven and earth.

How could there be anything on which they depend?

So earnest, they are consummate (ren 仁);

So profound, they are a bottomless abyss (yuan 淵);

So pervasive, they are tian (tian 天).

Only those whose own capacities of discernment and sagely wisdom extend to the powers of tian could possibly understand them. ${ }^{19}$

\section{The philosophical implications of a $q i$ 氣 cosmology}

The contemporary philosopher, Tang Junyi, has captured the coherence of the $q i$ worldview in identifying what he takes to be several distinctive and persistent features of Chinese natural cosmology. For Tang Junyi "natural" cosmology stands in contrast to the "supernatural" or "metaphysical" cosmology of classical Greece. In fact, the generic traits stated in Tang Junyi's own language describe in a different language many of the characteristics of the qi cosmology that I have tried to describe above. We will continue to explore and elaborate upon these distinguishing characteristics, using Tang Junyi's vocabulary as a way of testing my own attempt to describe Chinese cosmology, hoping in so doing to bring something of his insight and authority to this interpretive summary. These general propositions that seem to be commonsensical in operating within this worldview might serve us as a touchstone when interpreting the early philosophical literature. ${ }^{20}$

\footnotetext{
17 Great Commentary A9.

18 Berthrong (1998, p. 1).

19 Ames and Hall (2001, p. 113).

20 David Hall and I have elaborated upon many of these propositions in our interpretative studies of classical Chinese philosophy, especially Thinking from the Han (1998) and Anticipating China (1995).
} 


\section{"No fixed substratum"}

Tang Junyi suggests that in Chinese natural cosmology, there is "no appeal to a fixed substratum (wudingtiguan 無定體觀)." ${ }^{21}$ Of course this proposition is a rejection of the relevance of ontological disparity-the familiar reality and appearance distinction-in the Chinese cosmological sensibility. This difference has been discussed above in the distinction pursued between Greek elemental theories that entail ontological disparity, and the Chinese yinyang wuxing phasal cosmology. This commitment to an inherent, emergent sense of order rather than assumptions about an underlying permanent order might be restated positively as the perceived interdependence of "reforming and functioning (tiyong)," or alternatively, as the primacy of process and change over form and stasis.

This contrast between a substance and a process sensibility can be captured in the difference between "metaphysics" as the discovery of unchanging first principles on the one hand, and on the other, "the mapping out and forging a way forward in the world (dao 道)" ubiquitous in the Chinese philosophical texts. In this Chinese cosmology, order is not superordinate, standing independent of the world that it orders. Rather, the coherence of our experience emerges within the transformations occurring in the world around us.

\section{"The unceasingness of procreation"}

That the Book of Changes - the Yijing — has traditionally been give pride of place as first among the classics is revelatory of the primacy invested in process in the Chinese tradition, contrasting rather starkly with the ontological intuition that "Only Being is" that we find at the center of Parmenides's treatise, The Way of Truth. Tang Junyi's second proposition that overlaps with this characterization of the processual flow of experience as being without initial beginning or end is captured in his phrase: "the unceasingness of procreation 生生不已觀" derived itself from the Yijing's “ceaseless procreating is what is meant by 'change' 生生之謂易."22 Experience is continuous, is historicist, and is naturalistic in the sense of having no appeal to any metaphysical or supernatural source. Meaning is emergent in the transactions among the unique things that constitute the world.

The Yijing defines sagacity as the effective integration of the human experience into the operations of nature:

The heavens and the earth are in flux and undergo transformation, and the sagely imitate these processes. ${ }^{23}$

Quite specifically, the formal aspect of this human experience-both physical and conceptual-resides within and is acted upon by the manifold processes of change:

\footnotetext{
21 Tang Jnuyi (1988a, p. 9).

22 Tang Junyi (1988b, Vol. 11, pp. 20-22). Great Commentary A5.

23 Great Commentary A11.
} 
The manifestation of flux and transformation is such that in the heavens it brings images to completion and on the earth it brings forms to completion. ${ }^{24}$

The phenomenal world in classical China is an endless flow, evidencing its formal character only as "trans-form-ation." In fact, the Great Commentary says explicitly that "spirituality is without squareness and change is without body 神無方 而易無體." ${ }^{25}$ Willard Peterson in interpreting this passage suggests that "To have no 'squareness' is to be not susceptible of being differentiated into parts and to be not adequately delimited by any conceptual bounds." 26 Spiritual insight must go beyond rationalization because change will never be contained or arrested by any formal structure. "Things" are in fact a processive and hence always provisional flux of "events," where the shifting dispositioning of these events is interactive and mutually shaping. ${ }^{27}$

\section{"The inseparability of the one and the many"}

Another proposition offered by Tang Junyi that is also entailed by the absence of any appeal to substratum is "the inseparability of the one and the many," or stated more elaborately, "the inseparability of uniqueness and multivalence, of continuity and multiplicity, of integrity and integration (yiduo bufenguan 一多不分觀)." 28 What Tang Junyi means by this expression is that if we begin our reflection on the emergence of cosmic order from the wholeness of lived experience, we can view this experience in terms of both its dynamic continuities and its manifold multiplicity, as both a ceaseless processual flow and as distinct consummatory events. It is one more example of the mutual implication of binaries that characterizes all phenomena in the natural world - in this case, particularity and the totality. That is, any particular phenomenon in our field of experience can be focused in different ways: on the one hand it is a unique and persistent particular, and on the other, since it is constituted by its relationships, it has the entire cosmos and all that is happening implicated within its own particular pattern of relationships. For example, this person is uniquely who she is as distinct from other people, yet her magnitude is such that in giving a full accounting of the social, natural, and cultural relationships that constitute her, we must exhaust the cosmic totality.

A process worldview is one of radical contextuality, where the embedded particular and its context are at once continuous and distinct. This focus-field relationship is captured in the language of daode 道德—the field of experience $(d a o)$ and the myriad insistent particulars $(d e)$ that constitute it - as another way of

\footnotetext{
${ }^{24}$ Great Commentary A1.

25 Great Commentary A4.

26 Peterson (1982, p. 103).

27 In fact, at least as early as the Ming dynasty, the Chinese expression for "thing," dongxi 東西, is literally "east-west," underscoring the relational and contextual understanding that attends Chinese phenomonological perceptions.

28 Tang Junyi (1988a, p. 16).
} 
expressing the inseparability of the one and the many. In the Yijing, this sense of the mutuality of oneness and manyness is captured in the image of the four seasons which are at once distinct from each other and yet continuous:

In their flux (bian) and in their continuity (tong) the processes of nature are a counterpart to the four seasons. ${ }^{29}$

This notion of the inseparability of continuity and multiplicity is necessary to understand the claim we find throughout the early philosophical literature about the "oneness" of things, or of becoming "one" with things, often stated as a kind of achievement.

\section{Disambiguating the notion of "one"}

But "one" is an ambiguous term, and means something quite different in a process worldview than it does when we appeal to substance ontology. Sorting out which of the following connotations of "one" are properly in play in the qi cosmology will enable us to begin to distinguish between a more appropriate vocabulary for Chinese cosmology, and one that might be misleading.

We might parse these connotations of "one" into two different ranges of meaning that are distinguishable by the way in which things are thought to be related. One familiar range of meaning that we might associate with Aristotle entails a kind of extrinsic relatedness that allows things to stand independent of each other, while at the same time having some essential and universal defining characteristic that allows them to be subsumed into some single whole, a species or genera. All individual human beings are alike rational creatures which allows them to be summed as the species, "homo sapien." Humanity shares the characteristic of being a warm-blooded species that allows it to be summed into the genera, "mammals." Such an understanding of things makes them discrete and quantifiable. Things are individually exclusive and yet sortable into natural kinds by appeal to essential characteristics. The tree of these species and genera ultimately yield up a universea single ordered cosmos of parts and whole. This discrete and quantifiable understanding of "one" is most relevant to the substance worldview that has had a certain prominence in the Western philosophical narrative. In this ontological model, many are derivative of the one identical form.

The other certainly less familiar range of meaning of "one" entails an intrinsic and constitutive rather than an extrinsic relatedness that allows for the interdependence of things. In this cosmological model, it is the holographic entailment of the context within each always unique particular that requires an entertainment of the full complexity of particular things. To really know any particular person is to know the entire cosmos in a particular way and from a particular point of view.

In their irreducibly communal identity, human beings are each a unique loci of a range of more or less meaningful roles and relationships that collaborate to constitute them as meaningful persons. Each person is in fact a "field of selves."

29 Great Commentary A6. 
When persons step up, the whole web of their relationships-family, friends, mentors, colleagues, compatriots-step up with them. Personal "integrity" then is consummatory: the ongoing creative process of "becoming productively one" within these constitutive relationships with other persons. In so doing, one becomes ren 仁, or a "consummate person" (L. com- "together" and summa "the highest").

This sense of "one" also entails a process of individuation. With effort persons achieve meaningful relationships within their families and communities, and as they become an object of increasing deference, they become a "distinctive" and indeed "distinguished" member of the community. "One" in this world is also continuity with each other, and integrity means "becoming one together." And "one" certainly entails the quality of being uniquely authentic and genuine. This relational, interdependent, and qualitative understanding of "one" is more relevant to the process worldview in which one and many are two ways of looking at the same reality.

When we think of the "myriad things (wanwu)" as the proffered image of the Chinese worldview, notions of particularity, uniqueness, and continuity all have relevance. But it is important to understand this distinction between extrinsic and intrinsic relatedness as the difference between a substance and process worldview rather than as grossly the "West" and "China." Although a fair argument can be made that substance ontology has been a dominant theme in Western metaphysics, traditions such as American pragmatism are committed to a processual understanding of the human experience. $\mathrm{C}$. S. Peirce's notion of "synechism," for example, underscores the importance of continuity in explaining the nature of the world around us. In his Principles of Psychology, William James gives us a decidedly relational conception of "self." And John Dewey's notion of "individuality" like the Confucian "consummate person (ren)" is the emergence of a distinguished person though the cultivation of efficacious relations.

Extrinsic relatedness allows for a personal autonomy in which one's integrity is prior to the relationship and where the dissolution of a relationship leaves the remaindered participants intact. However, in a world of intrinsic relations, it is the relationships themselves that constitute the persons involved. Indeed, the individual is an abstraction from these constitutive relations. Hence, the dissolution of these relations is surgical, diminishing both parties to the degree that this particular relationship has been an important source of their emergent and continuing identity. Under such disintegrating circumstances, people quite literally "break up," "separate," and "divorce" — and become less in doing so.

The vocabulary of a single-ordered cosmos - the uni- of universal, universe, uniformity, unity, univocality - is helpful only by contrast in understanding $q i$ cosmology. In early Greek philosophy, the term "kosmos" connotes a clustered range of meanings, including arche (originative, material and efficient cause/ ultimate undemonstrable principle), logos (underlying organizational principle), theoria (contemplation), nomos (law), theios (divinity), and nous (intelligibility). In combination, this cluster of terms conjures forth some notion of a single-ordered Divine universe governed by natural and moral laws ultimately intelligible to the human mind. ${ }^{30}$ But those essentializing connotations of "one" that would allow for

\footnotetext{
30 For most of the Presocratics, kosmos was divine, and for both Plato and early Aristotle, kosmos was the "visible God (horatos theos)."
} 
strict identity and a decontextualizing discreteness-a final atomistic separation between the one and the many, and among the many themselves-would not be appropriate to what is ultimately an unsummed and thus "acosmotic" Chinese cosmology. ${ }^{31}$ That is, the classical Chinese worldview will not accommodate a cosmos in which the "many" are determined by and thus reducible to a transcendent, independent "One." It will not allow for the dissolution of the myriad particularsthe kosmoi-into some higher reality.

The final separation between one and one, and by extention, one and many, arises from several different assumptions. The transcendence and ontological priority of some creative principle that stands independent of its creatures establishes the familiar "One-many," "Being behind the beings," "Reality behind appearances" dichotomy. As Tang Junyi states explicitly in attempting to describe the uniqueness of the Chinese religious sensibility:

The Chinese have not embraced the concept of 'Heaven (tian)' that has transcendent meaning. The pervasive idea that Chinese have with respect to tian is that it is inseparable from the world. ${ }^{32}$

A "real" essence posited as ontological ground for something else less real-the "real" mind or soul as ground for the transitory and less real body, the "real" God as ground for the transitory and less real world-makes the relationships that obtain among such essences extrinsic. Things defined by some given essence- the human soul, for example-begin as separate, independent, and distinct entities that then come together into relationships. At the same time, it is the strict identity of things by virtue of this same shared essential condition that is the ground for universalism and univocity-for example, humanity as humanitas. Discreteness also emerges in the final separation between stasis and motion, between permanence and change, between being and becoming, where the former is in each instance the putative originating source of the latter.

In his reflection on Chinese natural cosmology, Tang Junyi goes so far as to take the peculiar holographic, interdependent relationship between "particulars" and their "totality" as the distinguishing contribution of Chinese culture broadly. It is

... the spirit of symbiosis and mutuality of particular and totality. From the perspective of understanding this means an unwillingness to isolate the particular from the totality (this is most evident in the cosmology of the Chinese people), and from the perspective of ties of feeling and affection, it means the commitment of the particular to do its best to realize the totality (this is most evident in the attitude of the Chinese people toward daily life). ${ }^{33}$

One need only reflect on the metaphor of "family" and family relatedness pervasive in the Chinese worldview to find a concrete example that would illustrate

\footnotetext{
31 In Anticipating China, David Hall and I coin the expression "acosmotic" to claim that "the Chinese tradition... does not depend upon the belief that the totality of things constitutes a single-ordered world" (pp. 11-12).

32 Tang Junyi is explicit in rejecting either "transcendence" or "absoluteness" as a condition of Chinese cosmology. See (1988a, p. 241).

33 Tang Junyi (1988a, p. 8).
} 
Tang Junyi's insight into the inseparability of one and many. It is because unique human beings emerge in the world within the context of multivalent family relationships that family is taken as the basic human unit, making any particular person in the family a conceptual abstraction.

\section{Propensity and contingency}

Identifying another distinctive feature of Chinese natural cosmology, Tang Junyi rejects the relevance of any kind of fatalism for this tradition-a cosmology that he characterizes as “nondeterministic 非定命觀.” Dao is presented in the Daodejing as the unfolding of a contingent world according to the rhythm of its own internal creative processes without any fixed pattern or controlling hand. For example, in Daodejing 51:

It is for this reason that all things (wanwu) honor way-making

And esteem particular character.

As for the honor directed at way-making (dao)

And the esteem directed at particular character $(d e)$,

It is really something that just happens spontaneously (ziran)

Without anyone having ennobled them.

A certain confusion arises because the term ming 命 that has conventionally been translated as "fate" or "destiny" occurs pervasively in the early literature, and in fact, appears in the received version of this chapter of the Daodejing. It is certainly true that there is a preoccupation with ming in this culture, but ming is not "fate" or "destiny" in the sense of some irrevocable predestined future, some "doom of the gods." Rather, ming is an always negotiated and, in degree, contingent future that emerges out of the interface between the forces of circumstance and the self-directing and spontaneously arising propensities of particular things or persons. That all things in the fullness of time are "fated" to expire is certainly true, but when and how and under what circumstances this comes to pass is a matter of always contingent, emerging conditions. This dao, always focused as one particular de or another, is the unfolding of a corridor of experience that reflects the collaboration of those participants in the world as they are located within interrelated and interactive dispositions, and who through their conduct, influence its outcomes.

A strict fatalism is not an option in a cosmology in which one and many are inseparable, since each unique particular shapes and is shaped by its contextualizing "many." In a world in which one and its context are mutually forming, no one aspect can have some unconditioned and determinative power over all others. "Cause" and "effect" are simply a matter of perspective rather than temporal priority. After all, does Newton shape Darwin, or Darwin, Newton?

\section{"Continuity between determinacy and indeterminacy, equilibrium and motion"}

Tang Junyi's also restates his "non-fatalistic" characterization of Chinese natural cosmology in a positive way. Rather than being driven by any kind of necessary, deterministic teleology, Chinese cosmology assumes the possibility of collaboration 
in a contingent and negotiated harmony (he 和) that succeeds by attempting to make the most out of the existing ingredients. Tang Junyi captures this collaboration in the proposition: "the continuity between determinacy and indeterminacy, equilibrium and motion”合有無動靜觀.”

Given that the world is without beginning or end, the goal in any and every moment is to achieve that kind of correlationality that optimizes the creative possibilities of the always unique situation. The achievement of an optimally productive harmony is not driven by some predetermined mechanical process, divine design, or rational blueprint. Rather such harmony is the result of an autopoeitic and spontaneous process (ziran 自然) in which the trajectories of unique "things" or "events" dispose themselves one to another most productively, with the energy for this ceaseless transformation lying within the world itself.

Indeed, we must appreciate the importance of the indeterminate, transformative aspect of dao. Daoist cosmogony does not entail the kind of radical initial beginning from a single source we associate with those metaphysical cosmogonies that describe the triumph of Order over Chaos. In fact, the Zhuangzi's well-known account of the death of Lord Hundun 混沌—often translated unfortunately as "Lord Chaos," but perhaps better rendered positively as "Lord Spontaneity"-provides a rather strong Daoist objection to such a "One-behind-the-many" reading:

The ruler of the North Sea was "Swift," the ruler of the South Sea was "Sudden," and the ruler of the Center was "Hundun, or Spontaneity." Lords Swift and Sudden had on several occasions encountered each other in the territory of Lord Spontaneity, and Spontaneity had treated them with great hospitality. Swift and Sudden, devising a way to repay Spontaneity's generosity, remarked that: "Everyone has seven orifices through which they can see, hear, eat, and breathe. Spontaneity alone is without them." They then attempted to bore holes in Spontaneity, each day boring one hole. On the seventh day, Spontaneity died. ${ }^{34}$

The expression "hundun" (or huntun), requires comment. Angus Graham in rendering this anecdote into English refuses to translate hundun at all, insisting it must not be confused with what we generally mean by "chaos:"

In Chinese cosmology the primordial is not a chaos reduced to order by imposed law, it is a blend of everything rolled up together; the word is a reduplicative of the type of English "hotchpotch" and "rolypoly," and diners in Chinese restaurants will have met it in the form "wuntun" as a kind of dumpling. ${ }^{35}$

For "wuntun," dollops of minced meat and vegetables are enfolded into amorphous wrappers which are then immersed to cook in rapidly boiling water. This pot full of tasty "wuntuns" tumbling about wildly in the roiling water, then, is the Chinese happy image of indeterminacy, or "chaos."

\footnotetext{
34 Zhuangzi 21/7/33; compare Graham (1981, pp. 98-99) and Watson (1968, p. 97).

35 Graham (1981, pp. 98-99).
} 
But why according to the Zhuangzi should one not wish to bring order out of hundun $?^{36}$ A reasonable question, indeed, if hundun were in fact the confusion and disarray-the formless surds-that other cosmogonies describe as primordial Chaos. In this parable, however, Hundun is to be understood relationally as the indeterminate aspect residing within the boundaries of north and south. Prior to Lord Hundun's demise caused as it is by having order "suddenly" and "swiftly" imposed upon him, he is able to make his contribution of meaning by being a source of self-renewal from within. Indeed, Hundun as the locus of implicit "disorder" or "chaos" does not inhibit or subvert the self-ordering, self-organizing process; on the contrary, he stimulates it. This dynamic sense of order that, rather than separating what orders from what is ordered, locates the energy of change within the existing order by insisting that such order is always richly vague, attended as it always is by a chaotic aspect. This naturalizing of novelty problematizes any kind of causal reductionism or simple determinism, thus guaranteeing the open-endedness we associate with freedom and creativity.

Hundun is the integral indeterminacy honeycombing all construals of order that is necessary for the spontaneous emergence of novelty in a continuing present. Indeed, the imposition of order upon Hundun means the death of self-reconstrual and the novelty that attends it. Important here is that Hundun is a partner in the continuing production of significance rather than some independent primordial source of order. And it is the collaboration of Hundun as Spontaneity with Lords Swift and Sudden that makes the life-experience hospitable, deliciously uncertain and in degree, unpredictable.

To enforce any given design — any particular teleology — is simply selecting one of a myriad candidates for order and privileging that one design over the rest. Lords Swift and Sudden in imposing their order have, to the world's and their own detriment, transformed the unsummed and causally noncoherent dao into a singleordered world. Since any coercion in a situation entails a diminution in possibilities, coercion is always anathema to such optimization. In fact, not only have Lords Swift and Sudden killed Lord Hundun, they have for all intents and purposes, committed suicide themselves.

While the articulation and stabilizing regularity of any specific event anticipates the way in which it will continue to unfold, the chaotic aspect within the event itself defeats any notion of necessity or absolute predictability. The combination of pattern and uncertainty defeats the possibility of universal claims and renders precarious any globalizing generalizations. All we can depend upon is the relative stability of site-specific and particular expressions of order, with constant attention to variables at every level that might well amplify into large scale changes. Order so conceived is thus always unique and local.

The related proposition that underscores the contingent nature of emerging order is its underdeterminacy. That is, there is an indeterminate aspect ( $j i$ 幾) entailed by the uniqueness of each participant that qualifies order, making any pattern of order

\footnotetext{
36 In fact, in the commentary that the translator Legge (1891, p. 267) appends to his early English translation of the Zhuangzi, he opines: "But surely it is better that Chaos should give place to another state. 'Heedless' and 'Sudden' did not do a bad work."
} 
novel and site-specific, irreversible, reflexive, and in degree, unpredictable. All human beings might be similar enough to justify certain generalizations, yet each person is at the same time a unique, one of a kind. It is this uniqueness of each person that precludes the possibility of any logarithmic understanding of human conduct, and that keeps the definition of humanity an open-ended and ongoing proposition.

\section{No advancing without reversion}

There is an important sense in which Chinese processual cosmological order is both cyclical and recursive. Tang Junyi's proposition which would seem to resonate with this underdeterminacy of order is the notion that "there is no advancing without reversion 無往不復觀. ${ }^{37}$ Tang Junyi cites Daodejing 40 insisting that order is not linear but cyclical, so that nothing flourishes without subsequently subsiding and reverting to its origins: "It is reversing and returning that is the movement of dao. 反 也者道之動也.”38 Order is the unceasing movement of things on a continuum between correlative extremes. In monsoon China, the rivers dry up in winter only to fill up again in summer, to dry up once again the following winter.

Since all participants in the order are correlational, the unique particular cannot be separated from its context - focus cannot be separated from its field. Thus, any construal of order is recursive, a coming back upon itself. Quite literally, what goes around comes around. To pollute the world is to pollute one's own body; to enchant the world is to enchant one's own life. It is this recursion that punctuates process, distinguishing and consummating particular "events" within it. Great persons produce great worlds. The human experience itself is the turning of the seasons, where 60 years completes one full cycle from spring to the depths of winter, only to produce out of itself another cycle.

Appealing to the Daoist tradition to illustrate this insight, the Daodejing 16 observes:

In the process of all things emerging together (wanwu)

We can witness their reversion.

Things proliferate,

And each again returns to its root.

The flowering of this plant is a unique life, while in its withering it produces the compost necessary to nourish the roots of new life invested in its seeds. This movement is the observed cadence and regularity of the world around us as it expresses its inherent capacity for self-transformation. The "cyclical" process, while passing through familiar phases, is not replication. It is the unfolding of an endless spiral that evidences on the one hand persistent and continuing patterns, and on the other, novelty, with each moment having its own unique character. It is because "the path $(d a o)$ is made in the walking" that the emerging course of experience is the

\footnotetext{
37 Tang Junyi (1988a, p. 11).

38 The Guodian text has “to return 返” for “contrary, to reverse 反."
} 
collaboration between the always unique particular and the context in which it participates.

\section{Priority of radial center over boundaries}

A proposition that follows from this notion of consummating particularity is that there is a priority of a dynamic radial center over boundaries. Order begins here and goes there. Perhaps these several propositions proffered by Tang Junyi can be summarized in the claim that, in Chinese natural cosmology, everything is at once local and global.

Taking the Daoist vocabulary as an example, there are degrees of relevance established through extending patterns of deference. ${ }^{39}$ Hence we can describe the person, the family, the community, the world, in terms of centripetal centers that extend outward as radial circles, in degree subjective and objective, inner and outer, local and global. Through these patterns of deference one can experience what is distant (yuan 遠) and even what is at the furthermost reaches (taiji 太極), but one can never extricate oneself from one's particular perspective to discover some ultimate boundary on experience. The particularity and the temporality of experience precludes the very possibility of such fixed, ultimate boundaries. Experience is always entertained from some particular perspective within the experience itself. It is for this reason that repeatedly Daodejing chapters conclude with correlating, localizing expressions such as “故去彼而取此: Hence discarding that they secure this." 40

Tang Junyi has a proposition which again expresses this same idea of being born into and extending out from a particular and specific context: "The natural tendencies of the human being are in fact the way of tian 性即天道觀." 41 This claim is really only a more complex way of acknowledging the continuity between the human being and tian 天人合一, a continuity that is always historicist, genealogical, and biographical. To illustrate this point, Tang Junyi cites a passage from the Zuozhuan:

That the people get to be born into a world is what is called "the propensity of circumstances (ming).,"42

The reality and inescapability of having a particular perspective in that world is the point of Daodejing 47:

Venture not beyond you doors to know the world;

Peer not outside your window to know the way-making (dao) of tian... .

It is for this reason that sages know without going anywhere out of the ordinary,Understand clearly without seeing anything out of the ordinary,

\footnotetext{
39 See Hall and Ames (1998): chapter 3, and Ames and Hall (2003, pp. 36-53). See also the Glossary of Key Terms.

40 See Daodejing 12, 21, and 72, for example.

41 Tang Junyi (1988a, p. 22).

42 Zuozhuan Harvard-Yenching Concordance Series 234/13/2.
} 
And get things done without doing anything out of the ordinary.

"Knowing," "seeing," and "accomplishing" within one's experience requires extending oneself from where one is, because one is always somewhere. This extension is achieved through responsive and efficacious participation in one's environments, and through one's full contribution in the local relationships that in sum, make one who one is.

Said another way, dao as the way of becoming consummately human is not "discovered" by travelling to distant and exotic places and by experiencing strange and wonderful things. In fact, "leaving home" effectively puts at risk precisely those specific relationships that have been cultivated to constitute oneself as a viable perspective in the world, and sends one off in pursuit of what is already implicated within one-that is, the entire cosmos.

\section{References}

Ames, R. T., \& Hall, D. L. (2001). Focusing the familiar: A translation and philosophical translation of the Zhongyong. Honolulu: University of Hawai'i Press.

Ames, R. T., \& Hall, D. L. (2003). Making this life significant: a translation and philosophical interpretation of the Daodejing. New York: Balantine.

Berthrong, J. (1998). Concerning creativity: A comparison of Chu Hsi, Whitehead, and Neville. Albany: State University of New York Press.

Graham, A.C. (1981). Chuang-tzu: The inner chapters (Trans.). London: George Allen \& Unwin.

Hall, D.L., \& Ames, R.T. (1995). Anticipating China: Thinking through the narratives of Chinese and western culture. Albany: State University of New York Press.

Hall, D. L., \& Ames, R. T. (1998). Thinking from the Han: Self, truth, and transcendence in Chinese and western culture. Albany: State University of New York Press.

Legge, J. (1891). The texts of Taoism (Trans.). In Sacred books of the east. Oxford: Oxford University Press.

Lynn, R. J. (1994). The classic of changes: A new translation of the I Ching as interpreted by Wang Bi (Trans.). New York: Columbia University Press, 1994.

Peterson, W. J. (1982). "Making connections: 'Commentary on the attached verbalizations' of the book of change." Harvard Journal of Asiatic Studies, 42, 1.

Shaughnessy, E. L. (1997). I Ching: The classic of changes (trans). New York: Ballantine.

Tang, J. (1988a). "Zhongguo zhexuezhong ziranyuzhouguan zhi tezhi (The distinctive features of natural cosmology in Chinese philosophy)." Zhongxi zhexue sixiang zhi bijiao lunwenji (Collected Essays on the Comparison between Chinese and Western Philosophical Thought). Taipei: Xuesheng shuju.

Tang, J. (1988b). Complete works. Taipei: Xuesheng shuju.

Watson, B. (1968). The complete works of Chuang Tzu. New York: Columbia University Press. 